\title{
Legal Regulation of Public-Private Partnership in the Republic of Macedonia
}

\author{
Risto Rechkoski \\ University "St. Kliment Ohridski”, Bitola, Republic of Macedonia
}

\begin{abstract}
This paper deals with a very important issue, which concerns the possibility of establishing a public-private partnership (PPP), through which link is made between the public and the private sector, for the benefit of both sectors, which is a very important opportunity for the realization of different infrastructure projects, and of course tourism facilities can be created in this form. Particular attention is given to the legal regulation of this issue in the Republic of Macedonia. It is mainly expressed through the provisions of the Law on PPP, which makes a clear distinction between the public and the private partner. Public partner is a legal entity that gives an agreement for the establishment of a public private partnership. Private Partner is a domestic or foreign legal entity or natural person or consortium with whom the public partner concludes an agreement for a PPP.
\end{abstract}

Keywords: PPP, legal regulation, public partner, private partner, agreement

\section{Introduction}

Public-private partnerships (PPPs), in many countries are a key tool for the implementation of priority infrastructure projects. PPP can provide a much more rational and simpler way of implementing large infrastructure projects, and thus certainly influences the development of tourism. The importance of PPP is in: overcoming the problem of insufficient budget funds for realization of large projects; the pursuit of greater benefit on the basis of the use of know-how and the methods of work of the private sector; and the change the role of the public sector from a direct participant in an entity that appears as an organizer, controller, and regulator.

Basically, the idea for PPP is very simple: instead of the state, the private sector finances and builds the project, with the right to manage it for a certain period of time to recover the investment. After the end of that period, the project is handed over to the state. However, concessions are neither simple nor easy and risky way of realizing investment projects. There are not just concessions as PPPs, but also some other forms such as: build-operate-transfer (BOT), and private financial initiative (PFI) with which the private owner with his own funds build, maintains and manages the project, and eventually in the end returns it to the state. Although theoretically this is quite well established, in practice, these PPPs are very difficult to perform, and very rarely give the expected effects.

Risto Rechkoski, Dr. Sc., full professor, Faculty of Tourism and Hospitality-Ohrid, University "St. Kliment Ohridski”, Bitola, Republic of Macedonia.

Correspondence concerning this article should be addressed to Risto Rechkoski, Faculty of Tourism and Hospitality-Ohrid, University "St. Kliment Ohridski”, Bitola, Kej "Macedonia” N.95, 6000 Ohrid, Macedonia. 


\section{Law Frame for PPP in the Republic of Macedonia}

The PPP in the Republic of Macedonia is regulated by several laws. The Law on Concessions and PPPs ${ }^{1}$ from 2012, amended and amended in 2014 and 2015 is systematic law. This matter is also regulated with the Law on Institutions ${ }^{2}$, as well as with the Law on Public Procurement ${ }^{3}$.

The Law on Concessions and PPP is composed of seven chapters, as follows:

(1) General provisions;

(2) Procedure for giving a concession for goods of general-public interest;

(3) Concession agreement for goods of general interest and agreement for the establishment of a PPP;

(4) Surveillance;

(5) Legal protection;

(6) Report and registers of assigned contracts;

(7) Transitional and final provisions.

In this law, material-legal provisions that regulate the issues of the case are stated, subjects, the form of the partnership, and the rules that apply to the contract for PPP. Although the law explicitly underlines the public interest as a central prerequisite for concluding a PPP, its provisions are aimed at maintaining a balance between public and private interest, which crossed each other upon each contract conclusion.

With Law, contracting parties, the public and private partners, are completely equal, but they carry quite different characteristics and obligations. On one hand is the public partner, as a legal entity that gives the PPP agreement. It may be the Republic of Macedonia, the designated municipality, the City of Skopje and the municipalities in the City of Skopje, the public enterprises, the public institutions, the trade companies established by the Republic of Macedonia, the municipality, the City of Skopje or the municipalities in the City of Skopje, as well as the companies on which the state or the bodies of the municipality, the City of Skopje and the municipalities in the City of Skopje, through their ownership, have direct or indirect influence, as well as other legal entities that perform public authorizations according to the laws.

On the other hand, the private partner is represented by a domestic or foreign natural person, legal entity or a consortium, which concludes a PPP contract with the public partner, or for this goal establishes a company for special purposes.

According to the law, PPP can be established in four forms, such as:

- Concession for public works;

- Concession for public service;

- Contract for public procurement of activity;

- Contract in the form of a public procurement for service.

Taking into account the legal framework, there are three relevant institutions working in the area of concessions and PPPs.

One of them is the Public Procurement Bureau, considering that, in accordance with national legislation it carries out "matters related to the development of the public procurement system, as well as the provision of

\footnotetext{
${ }^{1}$ Law on Concessions and Public Private Partnership, "Official Gazzete of the Republic of Macedonia". N. 6/12, 144/14, 33/15, $104 / 2015$.

${ }^{2}$ Law on Institutions, "Official Gazzete of the Republic of Macedonia”. N. 32/05, 120/05, 51/11.

3 Law on Public Procurement, "Official Gazzete of the Republic of Macedonia". N. 136/2007, 130/2008, 97/10, 53/11, 185/11, $15 / 13,148 / 13,28 / 14,43 / 14,130 / 14,180 / 14,78 / 15,192 / 15,27 / 16,120 / 16,165 / 2017$.
} 
rationality, efficiency and transparency in the implementation of public procurement". Although there is no reference to concessions in the Law on Public Procurement, attention must be paid to the fact that, according to EU legislation, as shown in certain cases in the case law of the European Court of Justice and in the doctrine developed by the European Commission, concessions and PPPs are included in the concept of public procurement, although concessions are excluded from the scope of Directive 2004/17/ EC, and only public activities, works concessions are covered by Directive 2004/18/EC.

In fact, in the Strategy of the Public Procurement Bureau, in the section titled "Goals and priorities-Improving the legal framework", it is stated that: "The Public Procurement Bureau will seriously consider the possibility of taking concessions for activities and concessions for services and put its integration into the public procurement system". Also, in Goal 5 of the Action Plan it is stated that it is responsible for the analysis of the regulations on concessions for services and activities, works. ${ }^{4}$ However, the practical implementation of such provisions is still lagging behind, and because of that, it is often overlapping of institutional competencies between the Ministry of Economy and the Ministry of Finance.

Another important institution in the field of concessions and PPPs is the Ministry of Economy of the Republic of Macedonia, which, in accordance with the Law on Concessions and PPP, performs the following competencies:

- Develop and implement measures and activities in order to achieve and maintain a fully transparent and efficient system for PPP;

- Run and maintain the register of given contracts for the establishment of a PPP;

- Prepare proposals for amendments to the regulations in the area of PPP, and provide instructions for the implementation of this Law;

- Organize and implement education and training about PPP for all participants in the process;

- Monitor, analyze, and provide expert assistance and opinion on the implementation of procedures;

- Monitor, analyze, and study current European and global trends, knowledges, and experiences in the field of PPP, etc.

Ministries of Finance, Transport and Communications, Health, Culture, etc. with their representatives are included in the Council for Public Private Partnership, which has an advisory role to the Government of the Republic of Macedonia in the field of PPP, promotes PPPs, proposes PPP projects, and gives an initiative with proposals for amendments of regulations of this area.

\section{Advantages and Risks of PPP}

PPPs are often used to fund various projects in EU countries. Based on the experiences from numerous examples of successful PPPs, the following basic benefits and advantages have been identified:

- Accelerated infrastructure construction;

- Better public services;

- Increased efficiency (reduced project life cycle costs);

- Better risk allocation;

- Faster implementation of projects;

- Creating additional income;

\footnotetext{
${ }^{4}$ Action Plan for Implementation of the Strategy of the "Public Procurement Bureau", http://bjn.gov.mk/mk/root/strategy.html.
} 
- Improved management.

\section{Situation in Macedonia in the Field of PPP}

In Republic of Macedonia according to the availability of data in the PPP segment, a different situation can be established.

In terms of the BOT model, there are few projects that are taken; and it is important that they properly prepared and the procedures are correct. The example of the Concession for the airport system in Macedonia through the Ministry of Transport is successful example. This project has a direct implication in the development of tourism in the Republic of Macedonia.

In 2008, the Government, through the Ministry of Transport, signed an agreement with the Turkish company-Tepe Aufen Ventures (TAV) for 20 years, during which the company should manage two existing airports in Macedonia: the Skopje airport and the "St. Apostle Paul" in Ohrid. The planned works included the construction of a new terminal building in Skopje, expansion of the airplane runway, a new administrative building and a new access road with parking places, which increased the capacity of the Skopje airport with projected goal to 4 million passengers per year.

Concerning the Ohrid airport, the terminal building and the VIP salon have been modernized. The concession agreement included the construction of a third airport, a cargo airport near Stip ${ }^{5}$, in eastern Macedonia. The total amount of the investment was projected at around $€ 200$ million, from which 30 to 40 million $€$ was paid to the Concessor-Republic of Macedonia, over the entire 20 year concession period.

\section{PPP Functioning Through Giving Public Services in Macedonian Legislation}

The Law on Concessions and PPP states that the PPP is actually characterized by the obligation of the private partner to provide a public service for the beneficiaries, of the public partner's necessary prerequisites for providing a public service to the end-users and/or activities within its competence. The legislator defines the justification of the need for a PPP as a venture that benefits public interest (cost savings for the public partner, a higher standard of public service or other public amenities) that exceeds the benefits arising from the usual way of providing conditions for performing of public services. However, the forms of the venture referred in Art. 5 of the Law on Concessions and PPP, the conclusion that PPPs in the provision of public services to classical public services (education, culture, science, health, social protection, etc.) continue to persist that a much more appropriate regulation is the Law on institutions ${ }^{6}$, rather than the Law on Concessions and PPP. This conclusion is due to the fact that the Law on Concessions and PPP contains all the elements for investments by private entities/partners in order to continuously and more efficiently perform only this special type of public service that constitutes the concept of public service in the narrow sense of the word. It is about the services that the state is obliged to give to its citizens, and which are essential not only for the development, but also for the survival of the society, but whose giving will be more efficient if it is realized with the help of a private partner.

Thus, the Law on Institutions in its "terms definition" defines the key terms regarding this matter, "agreement on joint establishment of an institution" is a contract concluded between two or more co-founders

\footnotetext{
5 This activity with appropriate anexes is being put on hold.

${ }^{6}$ Rechkoski, R.: Principles of public administration, Ohrid, 2012.

7 Article 2, par. 1.
} 
of the institution that regulates the mutual relations of the co-founders, in this way the legislator leaves the possibility of concluding a classic PPP contract in the provision of public services; "Interesting or functional connection" is the connection of institutions of the same or related activity for the purpose of joint performance of the core activity or for the purpose of achieving more rational and economical performance of the core activity. This would mean the possibility of joining a private and public institution for the purposes that are common for concluding a PPP.

Similar to the Law on Concessions and PPP, and the Law on Institutions, an obligation to submit a financial guarantee by the private partner is determined. ${ }^{8}$

Furthermore, in the common forms of investment in an institution, the Law determines the obligation to conclude a special type of agreement for joint establishment of an institution that has the character of a contract for an cooperation, but further, the rights and obligations regarding the performance of contractual obligations that imply the performance of a public service have the character of a administrative contract.

The Law on Institutions contains numerous modalities for cooperation or joint performance of the public activity by the public and private partners, but unfortunately this Law, although it was adopted in 2005, as a lex generalis, is not so used in the practice of the functioning of public services in Republic of Macedonia.

On the contrary, in order to achieve the goal of privatization of public services or their modernization and increase of efficiency through investments of private entities, the provisions of the separate laws regulating the activities of public services separately are used, for example the Law on Health Protection, the Law on Higher Education, The Law on Secondary Education, the Law on Culture, etc., which is completely wrong and unjustified.

In this way, it is difficult to ensure uniformity in the creation of PPPs in the public sector as a whole. The insufficient use of the existing legislation leads to phenomena that point to the fact that in the Macedonian public sector there are actually no real examples of PPPs, but only a classical privatization of "more income attractive" public services. For example, in education, there are examples of founding only of classical private institutions, not mixed ones. Same is the case with health care, as well as in the field of child care, care for the elderly, etc. Efforts to privatize the activity in the public health institutions are visible, but in this case not about PPPs.

\section{Conclusion}

From all above in the paper, it can be concluded that:

(1) PPP as a form or model represents one of the most important types of cooperation that enables and seeks to link the public performance of services with democratic responsibility to the authorities within a state, with the management skills and the economy that the private sector carries on. The various models on the basis of which the cooperation and the connection of the public and the private sector can be established is not always that simple and easy because, in this kind of cooperation, on the one hand is the entire state apparatus, and on the other hand, the private sector.

(2) The Law on Concessions and PPP testifies the attempts of the Republic of Macedonia for establishing the proper basis on which it will be founded and developed such cooperation. The legislation as well as the institutional setup of state institutions in this segment is set to a satisfactory level, so that what remains to be

${ }^{8}$ Article 17. 
realized in the future is successful projects of the public and private sector, especially at the local level where PPP is considered as one of basic ways of getting out of the crisis that affected the local authorities by implementing the process of decentralization and stopping budget subsidies, and also with this the process of tourism development will increase.

(3) In the countries of the South East Europe, as well as in the world economies in terms of their successful implementation of PPP, functional and feasible projects can be found on the one hand, but also numerous failures and falls can be found, especially when it comes to major investment ventures that require more time, finances, and resources. The same is the case with the Republic of Macedonia. One of the successful examples that can be pointed out is transformation of airports.

(4) The fact is that PPP is a real, feasible, and applicable model of cooperation between the two crucial sectors within each state - public and private.

(5) The construction of such crucial infrastructure projects certainly has contributed to the development of tourism in the Republic of Macedonia and the efforts for further development of this activity should continue.

\section{References}

Action Plan for Implementation of the Strategy of the "Public Procurement Bureau". (2012). http://bjn.gov.mk/mk/root/strategy.html

Belichanec, T., \& Klimovski, A. (2011). Corporative management. Skopje.

Brenck, A., Beckers, T., Heinrich, M., \& Von Hirschhausen, C. (2010). Public-private partnerships in new EU member countries of Central and Eastern Europe. EIB Papers, 10(2), 82-112.

Georgievski, S. (2009). New Macedonian concessions and the law on concessions and public private partnership, the need for further improvement? Lex Localis, 7(2), 159-160.

Law on Concessions and Public Private Partnership. "Official Gazzete of the Republic of Macedonia". N. 6/12, 144/14, 33/15, $104 / 2015$

Law on Institutions. "Official Gazzete of the Republic of Macedonia". N. 32/05, 120/05, 51/11

Law on Public Procurement. "Official Gazzete of the Republic of Macedonia". N. 136/2007, 130/2008, 97/10, 53/11, 185/11, $15 / 13,148 / 13,28 / 14,43 / 14,130 / 14,180 / 14,78 / 15,192 / 15,27 / 16,120 / 16,165 / 2017$

Rechkoski, R. (2012). Principles of public administration. Ohrid.

Riess, A. (2005). Deputy head of the Economic and Financial Studies Division of the EIB: Is the PPP model applicable across sectors? EIB Papers, 10(2), 10-31. 